\title{
Prevalence of Cervical Facet Joint Pain in Chronic Neck Pain
}

\author{
Laxmaiah Manchikanti, MD*, Vijay Singh, MD**, Jose Rivera, MD\# and Vidyasagar Pampati, MSc ${ }^{\# \#}$
}

Neck pain is considered to be one of the most common chronic pain conditions in modern society. Various structures identified as capable of transmitting pain in the cervical spine include facet joints, intervertebral discs, nerve root dura, ligaments, fascia, and muscles. The prevalence of cervical facet joint pain in patients with chronic pain after whiplash has been determined as $54 \%$ to $60 \%$. However, the prevalence of chronic cervical facet joint pain has not yet been determined in a heterogenous population or in patients with cervical spine pain of idiopathic origin in a controlled environment.

This study evaluated 160 patients seen in one interventional pain management practice in a non-university setting. Cervical facet joints were investigated with diagnostic blocks using lidocaine $1 \%$ preservative free initially, followed by bupivacaine $0.25 \%$, usually 2 to 4 weeks apart.

The study population consisted of 76 women and 30 men aged $43 \pm 13$ years of age (mean \pm SD). Mode of onset of neck pain was determined as following a traumatic incident in $48 \%$ of the patients, whereas it was with gradual onset without an identifiable specific incident in the remaining 55 patients (52\%). Eighty-one or $70 \%$ of the patients (70\%) reported a definite response to lidocaine blocks. Confirmatory blocks with bupivacaine were performed in 81 patients with 64 patients with $60 \%$ of the total sample, or $79 \%$, of the lidocaine-positive group reporting definite response with improvement in their pain. Thus, a prevalence rate of facet joint pain in chronic neck pain was determined to be $60 \%$ (95\% CI, 50\%-70\%), with a false positive rate of controlled diagnostic blocks of $40 \%$ (95\% CI, 34\%-46\%).

Keywords: Cervical facet joints, chronic neck pain, zygapophysial joints, headache, lidocaine, bupivacaine, controlled diagnostic blocks, false positive rate, prevalence
Neck pain, though not as common as low back pain, is encountered frequently. It is considered one of the most common chronic pain conditions and a major problem in modern society. Côté et al $(1,2)$ in evaluating neck pain and its related disability, reported that in the Canadian population, the estimated lifetime prevalence as 67\%, point prevalence of $22.2 \%$ and $14 \%$ prevalence of high pain intensity with disability. Croft et al (3) in a longitudinal study in the general population, in a sample made up of 7,669 adults aged 18 to 75 years, in the United Kingdom, with no current neck pain, reported a 1-year incidence of estimated cumulative episodic neck pain of $17.9 \%$. Studies

From Pain Management Center of Paducah, Paducah, Kentucky and Pain Diagnostic Associates, Niagara, Wisconsin. *Dr. Manchikanti is the medical director, "Dr. Rivera is an interventional pain physician and ${ }^{\# \#} \mathrm{Mr}$. Pampati is the statistician at the Pain Management Center of Paducah and **Dr. Singh is the medical director of Pain Diagnostics Associates. Address Correspondence: Laxmaiah Manchikanti, MD, 2831 Lone Oak Road, Paducah, KY 42003. E-mail: drm@asipp.org have reported that $15 \%$ of whiplash patients suffer severe pain for 1 to 3 years and between $26 \%$ and $44 \%$ of the whiplash patients develop long-term problems (4).

Kuslich et al (5) identified facet joints as capable of transmitting pain in the low back, along with intervertebral discs, nerve root dura, ligaments, fascia and muscles. Manchikanti et al (6) evaluated relative contributions of various structures in chronic low back pain and showed that facet joint pain was diagnosed in $40 \%$ of the patients, whereas in $26 \%$ of the patients, discogenic pain was diagnosed. Various structures in the cervical spine, including facet joints, intervertebral discs, dorsal root ganglia, muscles and ligaments are capable of causing headache, neck pain and shoulder pain. Pawl (7) in 1977 reported the reproduction of pain in patients with neck pain and headache after injections of hypertonic saline into the cervical facet joints. However, the cervical facet joints attracted relatively little attention as possible sources of neck pain and referred pain in the 1970s and early 1980s. Multiple authors have described the management of cervical facet joint pain; however, mostly in uncontrolled reports (8-11). Bogduk and Marsland (12) in 1988 
described cervical zygapophysial joints as a source of neck pain. In 1992, Aprill and Bogduk (13) reported the prevalence of cervical zygapophysial joint pain in consecutive patients with intractable neck pain as $25 \%$ with the possibility of as high as $63 \%$. In 1993, Barnsley and Bogduk (14) reported the specificity of medial branch blocks in the diagnosis of cervical zygapophysial joint pain. Barnsley et al (15), in 1995, determined the prevalence of cervical zygapophysial joint pain in patients with chronic neck pain after whiplash, using double blind, controlled, diagnostic blocks in $54 \%$ of the patients. In 1996, Lord et al (16) using a diagnostic double blind placebo controlled local anesthetic blocks in patients with chronic neck pain after whiplash reported overall prevalence of cervical zygapophysial joint pain as $60 \%$. In a retrospective evaluation Speldewinde et al (17) reported $36 \%$ prevalence of facet joint pain in patients suffering with chronic neck pain. However, they acknowledged that their estimate was conservative and low.

In spite of the multiple publications in the 1990s, neck pain without neurological signs still attracts diagnosis such as cervical spondylosis, "soft tissue injury,” ligament injury and "somatic neck pain." Thus, chronic neck pain continues to remain one of the arcane areas of medicine in which accurate, anatomic diagnosis is the exception rather than the rule (14). It has been described that imaging studies, physical examination and electrodiagnostic studies and clinical presentation are notoriously unreliable in making a precision diagnosis and pinpointing the actual source of pain other than in cases of nerve root compression. Over the years, it has been shown clearly that cervical facet joint pain can be diagnosed by anesthetizing the joint suspected of being symptomatic and then evaluating the patient for loss of pain (14).

Even though the prevalence of cervical facet joint pain has been shown to be a common occurrence in multiple reports, the controlled studies determined the prevalence of chronic cervical facet joint pain after whiplash only $(15,16)$. Other studies $(13,14)$ also evaluated traumatic onset of neck pain. Only two evaluations, one prospective (12) and the second one retrospective (17) included evaluation of idiopathic neck pain. Hence, this study was undertaken to determine the prevalence of cervical facet joint pain using controlled diagnostic blocks in a sample of patients with chronic neck pain presenting to an interventional pain management practice setting.

\section{METHODS}

The study population consisted of 106 patients seen in one interventional pain management practice, during 2001, by one physician in a non-university setting. All the patients were scheduled to undergo cervical facet joint nerve blocks for the diagnosis and management of chronic neck pain with or without headache, with or without upper extremity pain. During this study period of one year, 365 patients were evaluated by one physician and 875 patients were evaluated at the center. Patients younger than 18 years or older than 90 years, those who exhibited neurological deficits, those who had pain for less than 6 months or had undergone neural blockade in the past, were excluded. Evaluation included completion of a standard comprehensive pain questionnaire, history, physical examination, psychological evaluation, and evaluation of the results of all procedures and investigations performed. The nature of the study and the potential hazards of the procedures were explained to all patients, all of whom consented to participate. Facet joints were investigated with the diagnostic blocks using $0.5 \mathrm{~mL}$ of lidocaine $1 \%$ preservative free initially, followed by $0.5 \mathrm{~mL}$ of bupivacaine $0.25 \% 2$ to 4 weeks later. The blocks were performed on the ipsilateral side in patients with unilateral pain, or bilaterally in patients with bilateral or axial pain. All of the blocks were performed by one investigator in an operating room equipped with an image intensifier with the patients in the prone position. Intravenous access and mild sedation with midazolam was carried out. Under intermittent fluoroscopic visualization, each block was performed at appropriate medial branches innervating the facet joints under investigation. C2/3 to C6/7 were individually assessed using a 22-gauge 2-inch spinal needle. Following the blocks, the patient was examined and movements, which were painful prior to medial branch blocks, were performed. A definite response was defined as substantial with at least $75 \%$ relief of pain in the symptomatic area following the local anesthetic block. Confirmatory blocks using bupivacaine $0.25 \%$ were performed at the same levels as the first injection if definite relief was obtained. The response of relief of at least 90 minutes with lidocaine and 3 hours with bupivacaine were considered as positive responses. In addition, response with bupivacaine must have been always longer than the response with lidocaine. All the other responses were considered as negative.

Date was recorded on a database using Microsoft ${ }^{\circledR}$ 
Access ${ }^{\circledR}$. SPSS ${ }^{\circledR}$ for Windows (Statistical Product and Service Solutions), REL 9.1 1999, Chicago; SPSS Inc. was used to generate the frequency tables.

\section{RESULTS}

Each of the 106 patients receiving medial branch blocks consented to participate and were included in the study. The study population consisted of 76 women and 30 men aged $43 \pm 13$ years (mean \pm SD). Mode of onset of neck pain was determined as following a traumatic incident in 51 (48\% of the patients) and with gradual onset without any specific incident in 55 (52\% of the patients). Mean duration of pain was $7.7 \pm 1$ years. Fifteen percent of the patients presented with a history of previous cervical surgery.

All patients underwent cervical medial branch blocks with lidocaine. Eighty one or $70 \%$ of the patients reported a definite response to lidocaine blocks. Confirmatory blocks with bupivacaine were performed in each of these 81 patients. Of this group, 64 patients i.e., $60 \%$ of total sample or $79 \%$ of lidocaine-positive group reporting definite response with improvement in their pain. This latter group provides a prevalence rate of facet joint pain for patients with chronic neck pain presenting to an interventional multidisciplinary private pain management practice of $60 \%$ (95\% CI, 50\%-70\%). For the purposes of calculating false positive rate, all the patients who had no response to lidocaine were assumed to be true-negative and all the patients who had a positive response to lidocaine and negative response to bupivacaine were considered to be false positive. The resultant false positive rate was $40 \%$ (95\% CI, 34\%, 46\%) (Table 1).

\section{DISCUSSION}

Neck pain is one of the most common chronic pain conditions in modern medicine. Côté et al $(1,2)$ identified a point prevalence of neck pain in $22.2 \%$ of patients. Croft et al (3) observed a 1-year incidence of cumulative episodic neck pain of $17.9 \%$. Hartvigsen et al (18) demonstrated the 1 -year prevalence of neck pain can be as high as $40 \%$, with the prevalence for women slightly higher than those for men. Various population studies report the 1-year prevalence ranges from 26 to $60 \%$ (19, 20, 21). Two studies demonstrate similar one year prevalence rates for men and women; $17.5 \%$ for women and $16.5 \%$ for men by Takala et al (22) and 15\% for men with $17 \%$ for women by Lau et al (23). Hallgern et al (24) reported that patients with chronic pain constituted approximately $30 \%$ of all
Table 1. Results of single blocks (lidocaine) and double blocks (lidocaine and bupivacaine)

\begin{tabular}{lcc}
\hline & \multicolumn{2}{c}{ Double blocks } \\
& Positive & Negative \\
\hline Positive & 64 & 17 \\
Negative & & 25 \\
Prevalence & $60 \%$ \\
False positive rate & $40 \%$ \\
\hline
\end{tabular}

individuals experiencing chronic pain. Scheolkov (25) estimated that approximately $30 \%$ of the patients with neck pain will develop chronic symptoms. Takala et al (22) also estimated that for retired women, the prevalence of neck pain was 23\% whereas it was 30\% for retired men. Chronic neck pain following whiplash injuries is a common phenomenon. Johnson (4) showed that $15 \%$ of whiplash patients suffer severe pain for approximately 1 to 3 years. Approximately $26 \%$ to $44 \%$ of the patients also developed long-term problems, whereas $5 \%$ of the patients developed chronic, unremitting pain (4). Hildingsson and Toolanen (26) reported that $43 \%$ of the patients with whiplash injury continued to have symptoms sufficiently severe to interfere with their ability to work 2 years after their initial injury. Hodgson and Grundy (27) reported that $31 \%$ of the patients had symptoms even 10 to 15 years after the injury, even though most of them have settled their cases.

Fukui et al (28) showed referred pain distribution of cervical zygapophysial joints in cervical dorsal rami. Dwyer et al (29) mapped out specific locations of referred neck pain, while Aprill et al (30) confirmed the accuracy of pain charted by anesthetizing the medial branches of the dorsal rami above and below the symptomatic joint. Pawl (7) showed the ability to reproduce neck pain with headache after injection of hypertonic saline into the cervical facet joints in 1977. Cervical facet joints are innervated by the medial branches of the dorsal rami (31). Morphologically, the joint capsules are well innervated, receiving their nerve supply from the medial branches of the dorsal rami. Each medial branch segmentally innervates two facet joints (31). Ohtori et al (32) in evaluating the sensory innervation of the cervical facet joints in rats showed that the $\mathrm{C} 3-\mathrm{C} 4$ and $\mathrm{C} 5-\mathrm{C} 6$ facet joints were innervated by corresponding and adjacent segments (C5 and C6) directly, but the sensory nerve fibers supplying 
the $\mathrm{C} 1$ to $\mathrm{C} 2$ facet joint were derived from three segments (C1, C2, and C3). They showed that C5-C6 facet joints were innervated with sensory nerve fibers from the parasympathetic nodose ganglion. They also postulated that in rats, the sensory neurons may transmit pain sensation and regulate the autonomic response, but, because the number of neurons was few compared with the DRG neurons, the function in pain or autonomic regulation was thought to be little. Even then, they concluded that, "dual innervation" is present in the C5-C6 facet joint, which may explain some of the clinical events of neck pain responding to blockade of the stellate ganglion, if a similar innervation pattern is present in humans. Winkelstein et al (33) in an anatomical investigation of the human cervical facet capsule demonstrated quantitative evidence of substantial muscle insertions into the facet capsule ligament. They postulated that this may provide a possible mechanism for injury to this ligament-facet complex. Substance P (SP) and calcitonin gene-related peptide (CGRP) are sensory markers related to pain $(34,35)$. The presence of SP) and CGRP immunoreactive (IR) nerve fibers are present within the facet joint capsules (35-39). Ohtori et al (39) revealed the presence of calcitonin gene-related peptideimmunoreactive neurons in cervical facet joints. They also showed that the ratios of CGRP immunoreactive neurons in the C5 and C6 dorsal root ganglia were significantly higher than those in the C3, C4, C7, and C8 dorsal root ganglia in rats. Thus, in the physiological condition in rats, the neurons of the $\mathrm{C} 5$ and $\mathrm{C} 6$ dorsal root ganglia may have a more significant role in pain sensation of the facets than other dorsal root ganglion neurons. Inami et al (40) evaluated the role of intraarticular synovial folds in the cervical spine. He observed the presence of putative nociceptive fibers in cervical synovial folds supporting a possible role for these structures as a source of cervical facet joint pain.

Diagnostic blockade of a structure, with a nerve supply, that has the ability to generate pain can be performed to test the hypothesis that the target structure is a source of a patient's symptoms of pain $(41,42)$. True positive responses are only secured by performing controlled blocks. Ideally, these should use a placebo injection of normal saline. However, logistical and/or ethical considerations may prohibit the use of normal saline in conventional practice, particularly in the United States. Bogduk (41) proposed that blocks of a facet joint can be performed to test the hypothesis that the target joint is the source of the patient's pain by anesthetizing the target joint. Provocation of pain from a joint is an unreliable criterion, and relief of pain is the essential criterion. While facet joints can be anesthetized, either by administering intraarticular injections of local anesthetic or by anesthetizing the medial branches of the dorsal rami that innervate the target joint, true positive responses are only obtained by performing controlled blocks. As an alternative to placebo injections of normal saline, comparative local anesthetic blocks in which on two separate occasions, the same joint is anesthetized using two local anesthetics with different durations of actions, has been proposed (41-47). The use of comparative local anesthetic blocks has been validated and found to be robust when compared with a placebo injection $(46,47)$. Facet joints may be anesthetized either by intraarticular blocks or medial branch blocks (41, 42). Intraarticular injections are somewhat more difficult and time consuming than medial branch blocks because they require accurate placement of the needle within the joint cavity, with care not to overpenetrate the joint. In contrast, medial branch blocks are expeditious and carry no risk of over penetration. Further, joint entry may be impossible because of severe age-related changes, postsurgical status or posttraumatic arthropathy; however, no such processes affect access to the medial branches (42). Okada (48), in a serious of 142 arthrograms, showed a communicating pathway in $85 \%$ of the subjects between the facet joint and the interlaminar space, interspinous space, contralateral facet joint, paraextradural space or cervical extradural space when volumes in excess of 1 $\mathrm{mL}$ were used. In addition, extraarticular leakage also has been observed in up to $17 \%$ of the patients even when smaller volumes were used $(11,49)$. Thus, intraarticular injections may not be as specific as commonly believed. In contrast, with a medial branch block, the injectate reaches the target nerve and does not affect any other diagnostically important structures, such as the ventral ramus (14). Intraarticular injections may be more appropriate for intraarticular therapy. However, for diagnostic purposes, and, in particular, if radiofrequency neurotomy is proposed, medial branch blocks may be the ideal procedure. In addition, comparative local anesthetic blocks with intraarticular injections may have a drawback. It is unknown whether the placement of the local anesthetic near a relatively avascular environment, such as a joint space, affects its expected duration of action. In addition, cervical intraarticular injections have been associated with dorsal root ganglion, along with epidural penetration of the local anesthetic. Bogduk (41) described indications for diagnostic facet joint blocks, which included spinal pain for which no cause is otherwise evident and whose pain patterns resemble that of evoked pain in normal volunteers upon stimulation of the facet joints. 
In the new millennium, there is a preponderance of evidence demonstrating the existence of cervical facet joint pain $(10,12-17,28-30,48,50-53)$. However, detractors of cervical facet joint pain persist in claiming the lack of its existence. Ferrari (54), commenting on the study conducted by Sapir and Gorup (52) evaluating the effectiveness of radiofrequency medial branch neurotomy in litigant and non-litigant patients with cervical whiplash, stated that neither Sapir and Gorup (52) nor Wallis et al (53) demonstrated the presence of facet joint arthropathy. Further, Ferrari (54) claimed that what the previous authors had demonstrated is that if you insert a needle into someone's neck, some people then report less pain. They also stated that radiofrequency neurotomy does not describe what the pathology is, but it just describes that whatever structure is supplied by a certain nerve branch is no longer causing pain. Further, technological advancements have enhanced our understanding of the pathophysiology of cervical whiplash, if not idiopathic neck pain (52). High-speed cinevideo radiography has shown that the facet joint can be injured during cervical whiplash injury (55). Not only have numerous clinical studies demonstrated that cervical facet joints often are the source of neck pain after whiplash, but the prevalence of specific cervical facet joint involvement has also been reported (12-16). Furthermore, typical patterns of facet joint pain, derived from normal volunteers, also have been described. Radiofrequency medial branch neurotomy has been shown to reduce facet joint pain as treatment for cervical whiplash injuries (50-53).

The prevalence of cervical facet joint pain of $60 \%$ established in this study, in patients presenting to an interventional pain management practice setting, after failure of physical therapy, chiropractic, and medical management, is similar to the incidence reported by previous controlled trials in whiplash patients of $54 \%$ and $60 \%(15,16)$. The results are also similar to the study by Aprill and Bogduk (13) with prevalence of 63\% in patients with chronic post-traumatic neck pain. It was slightly higher than the reported prevalence in a retrospective evaluation (17). Thus, the prevalence of facet joint pain in chronic neck pain in a group of heterogenous patients with idiopathic and posttraumatic neck pain is similar to the prevalence of chronic neck pain following whiplash injuries. A significant proportion of patients presenting to an interventional pain management setting without a definite diagnosis are experiencing chronic neck pain of facet joint origin. In those instances, the appropriate diagnosis may be made by controlled comparative local anesthetic diagnostic blocks. The false positive rates of cervical medial branch blocks of $40 \%$ in this study is higher than the $27 \%$ previously reported (56). This result emphasizes the importance of controlled diagnostic blocks. We consider the results of this study to be generalizable to interventional pain management settings for patients with neck pain and no evidence of radicular involvement who have failed physical therapy, chiropractic management and medical therapy. Since there are no features or imaging studies that indicate whether a cervical facet joint is painful, we believe medial branch blocks are the only reliable diagnostic tool to diagnose chronic neck pain patients. However, the diagnosis of cervical facet joint pain, hinges on the validity of cervical facet joint blocks, which has both clinical and technical aspects (14). Our study used stringent clinical and technical criteria. Each block was performed with $0.5 \mathrm{~mL}$ of local anesthetic. The reliability of these blocks has been addressed under stringent, double-blind, controlled conditions in the past $(15,16$, 42-47). Further, the target specificity of cervical medial branch blocks in the diagnosis of cervical facet joint pain was also established (14). Barnsley and Bogduk (14) showed that the only structures anesthetized by cervical medial branch blocks are the target nerve itself and the adjacent periosteum. Based on the spread of the contrast medium indicating the spread of a similar quantum of local anesthetic, Barnsley and Bogduk (14) described the anatomy of the surrounding structures appears to prevent the spread of local anesthetic to any other diagnostically important structures. They also showed that the spread of local anesthetic into the overlying muscles was limited and variable. Barnsley and Bogduk (14) considered the argument that the fibers of semispinalis capitis outlined by the contrast medium could have been the source of pain, however, there were no known pathologic conditions that affect this discrete portion of the muscle that could render it a source of chronic pain. In addition, they also showed that other patients also obtained relief when the contrast medium failed to outline the semispinalis and covered the multifidus instead. As per Barnsley and Bogduk (14), unless one claims that chronic neck pain stems from the periosteum of the articular pillar, the inescapable conclusion must be that the relief of pain after cervical medial branch blocks are those structures innervated by the target nerve or nerves; the facet joints above and below the course of the nerve, the discrete fascicles of multifidus, semispinalis capitis, and semispinalis cervicis. Thus, contemporary evidence overwhelmingly supports that the cervical facet joints are the source of pain in those patients who obtain relief of pain consistently with controlled diagnostic blocks after cervical medial branch blocks. 


\section{CONCLUSION}

The results of this study show prevalence of facet joint pain in chronic neck pain as $60 \%$ in an interventional pain management setting. This study confirms the previous reports establishing facet joints as a common source of neck pain. The results of this study also echo previous concerns of reliability of uncontrolled single blocks, with a false positive rate of $40 \%$.

\section{ACKNOWLEDGMENTS}

We would like to thank Carla D. Beyer, RN, Kim S. Damron, RN and Renee C. Barnhill RN, clinical coordinators; Kimberly A. Cash, RT and Tammy L. Moss, RT; radiological technologists; Doris E. Brandon, CST, Sue R. Wilson, CST, Victoria L. Hicks, CST, surgical technologists; Marla K. Neihoff and Lorie A. Caldwell, medical records coordinators; and Tonie D. Hatton, transcriptionist, for their assistance in the completion of the study and transcription of the manuscript.

\section{REFERENCES}

1. Côté DC, Cassidy JD, Carroll L. The Saskatchewan Health and Back Pain Survey. The prevalence of neck pain and related disability in Saskatchewan adults. Spine 1998; 23:1689-1698.

2. Côté DC, Cassidy JD, Carroll L. The factors associated with neck pain and its related disability in the Saskatchewan population. Spine 2000; 25:11091117.

3. Croft PR, Lewis M, Papageorgiou AC et al. Risk factors for neck pain: A longitudinal study in the general population. Pain 20014; 93:317-325.

4. Johnson G. Hyperextension soft tissue injuries of the cervical spine: A review. J Accid Emerg Med 1996; 13:3-8.

5. Kuslich SD, Ulstrom CL, Michael CJ. The tissue origin of low back pain and sciatica: A report of pain response to tissue stimulation during operation on the lumbar spine using local anesthesia. Orthop Clin North Am 1991; 22:181-187.

6. Manchikanti L, Singh V, Pampati VS et al. Evaluation of the relative contributions of various structures in chronic low back pain. Pain Physician 2001; 4:308316.

7. Pawl RP. Headache, cervical spondylosis, and anterior cervical fusion. Surg Ann 1977; 9:391-498.

8. Hildebrandt J, Argyrakis A. Percutaneous nerve block of the cervical facets - A relatively new method in the treatment of chronic headache and neck pain. Pathological-anatomical studies and clinical practice. Manual Medicine 1986; 2:48-52.
9. Schaerer JP. Radiofrequency facet rhizotomy in the treatment of chronic neck and low back pain. Int Surg 1978; 63:53-59.

10. Dory MA. Arthrography of the cervical facet joints. Radiology 1983; 148:379-382.

11. Wedel DJ, Wilson PR. Cervical facet arthrography. Reg Anesh 1985; 10:7-11.

12. Bogduk N, Marsland A. The cervical zygapophysial joints as a source of neck pain. Spine 1988; 13:610617.

13. Aprill C, Bogduk N. The prevalence of cervical zygapophyseal joint pain. Spine 1992; 17:744-747.

14. Barnsley L, Bogduk N. Medial branch blocks are specific for the diagnosis of cervical zygapophyseal joint pain. Reg Anesth 1993; 18:343-350.

15. Barnsley L, Lord SM, Wallis BJ et al. The prevalence of chronic cervical zygapophysial joint pain after whiplash. Spine 1995; 20:20-26.

16. Lord SM, Barnsley L, Wallis BJ et al. Chronic cervical zygapophysial joint pain after whiplash. Spine 1996; 21:1737-1745

17. Speldewinde GC, Bashford GM, Davidson IR. Diagnostic cervical zygapophyseal joint blocks for chronic cervical pain. Med J Aust 2001; 174:174176.

18. Hartyigsen J, Bakketeig LS, Leboeuf-Yde C et al. The relationship between physical work-load and low back pain clouded by the "healthy worker" effect: A population based cross-sectional and 5 year prospective questionnaire study. Spine 2001; 26:1788-1793.

19. Bovim G, Schrader H, Sand T. Neck pain in the general population. Spine 1994; 19:1307-1309.

20. Brattberg G, Thorslund M, Wikman A. The prevalence of pain in a general population: The results of a postal survey in a country of Sweden. Pain 1989; 37:215-222

21. Rajala U, Keinänen-Kiukkaanniemi S, Uusimäki A et al. Musculoskeletal pains and depression in a middle-aged Finnish population. Pain 1995; 61:451457.

22. Takala J, Sievers K, Kalukka T. Rheumatic symptoms in the middle-aged population in south western Finland. Scand J Rheumatol Suppl 1982; 47:15-29.

23. Lau EMC, Sham A, Wong KC. The prevalence of and risk factors for neck pain in Hong Kong Chinese. J Public Health Med 1996; 18:396-399.

24. Hallgern RC, Greenman PE, Rechtien JJ. Atrophy of suboccipital muscles in patients with chronic pain: A pilot study. J Am Osteopath Assoc 1994; 12:10321039.

25. Scheolkov AP. Evaluation, diagnosis, and initial treatment of cervical disc disease. Spine State of the Art Reviews 1991; 5:167-176.

26. Hildingsson C, Toolanen G. Outcome after soft-tissue injury of the cervical spine: A prospective study of 93 car accident victims. Acta Orthop Scand 1990; 
61:357-359.

27. Hodgson S, Grundy M. Whiplash injuries: Their long-term prognosis and its relationship to compensation. Neuro Orthopedics 1989; 7:88-91.

28. Fukui S, Ohseto K, Shiotani M et al. Referred pain distribution of the cervical zygapophyseal joints and cervical dorsal rami. Pain 1996; 68:79-83.

29. Dwyer A, Aprill C, Bogduk N. Cervical zygapophyseal joint pain patterns: A study in normal volunteers. Spine 1990; 6:453-457.

30. Aprill C, Dwyer A, Bogduk N. The prevalence of cervical zygapophyseal joint pain patterns II: a clinical evaluation. Spine 1990; 6:458-461.

31. Bogduk N. The clinical anatomy of the cervical dorsal rami. Spine 1982; 7:319-330.

32. Ohtori S, Takahashi K, Chiba T et al. Sensory innervation of the cervical facet joints in rats. Spine 2001; 26:147-150.

33. Winkelstein BA, McLendon RE, Barbir A et al. An anatomical investigation of the human cervical facet capsule, quantifying muscle insertion area. J Anat 2001; 198:455-461.

34. Miletic V, Tan H. Iontophoretic application of calcitonin gene-related peptide produces a slow and prolonged excitation of neurons in the cat lumbar dorsal horn. Brain Res 1988; 446:169-172.

35. Otsuka M, Yanagisawa M. Does substance P act as pain transmitter? Trends Pharmacol Sci 1987; 8:506510.

36. Ashton IK, Ashton BA, Gibson SJ et al. Morphological basis for back pain: The demonstration of nerve fibers and neuropeptides in the lumbar facet joint capsule but not in ligamentum flavum. J Orthop Res 1992; 10:72-78.

37. Grönblad M, Korkala O, Konttinen YT et al. Silver impregnation and immunohistochemical study of nerves in lumbar facet joint plical tissue. Spine 1991; 16:34-38.

38. Suseki K, Takahashi Y, Takahashi K et al. Innervation of the lumbar facet joints. Spine 1997; 22:477-485.

39. Ohtori S, Moriya H, Takahashi K. Calcitonin generelated peptide immunoreactive sensory DRG neurons innervating the cervical facet joints in rats. J Orthop Sci 2002; 7:258-261.

40. Inami S, Shiga T, Tsujino A et al. Immunohistochemical demonstration of nerve fibers in the synovial fold of the human cervical facet joint. J Orthop Res 2001; 19:593-596.

41. Bogduk N. International Spinal Injection Society guidelines for the performance of spinal injection procedures: Part I. Zygapophysial joint blocks. Clin
J Pain 1997; 12:285-302.

56. Barnsley L, Lord SM, Wallis BJ et al. False-positive rates of cervical zygapophysial joint blocks. Clin $J$ Pain 1993; 9:124-130.

42. Bogduk N, Lord S. Cervical zygapophysial joint pain. Neurosurgery 1998; 8:107-117.

43. Boas RA. Nerve blocks in the diagnosis of low back pain. Neurosurg Clin North Am 1991; 2:806-816.

44. Bonica JJ. Local anesthesia and regional blocks. In Wall PD, Melzack R (eds). Textbook of Pain, Second edition. Churchill Livingstone, Edinburgh, 1989, pp 724-743.

45. Bonica JJ, Buckley FP. Regional analgesia with local anesthetics. In Bonica JJ (ed). The Management of Pain. Lea \& Febiger, Philadelphia, 1990; 2:18831966.

46. Barnsley L, Lord S, Bogduk N. Comparative local anesthetic blocks in the diagnosis of cervical zygapophysial joints pain. Pain 1993; 55: 99-106.

47. Lord SM, Barnsley L, Bogduk N. The utility of comparative local anesthetic blocks versus placebocontrolled blocks for the diagnosis of cervical zygapophysial joint pain. Clin J Pain 1995; 11:208213.

48. Okada K. Studies on the cervical facet joints using arthrography of the cervical facet joint. J Jpn Orthop Assoc 1981; 55:563-580.

49. Hove B, Gyldensted C. Cervical analgesic facet joint arthrography. Neuroradiology 1990; 32:456-459.

50. Lord S, Barnsley L, Bogduk N. Percutaneous radiofrequency neurotomy in the treatment of cervical zygapophysial joint pain: A caution. Neurosurgery 1995; 36:732-739.

51. Lord S, Barnsley L, Wallis B et al. Percutaneous radiofrequency neurotomy for chronic cervical zygapophyseal joint pain. $N$ Engl J Med 1996; 335:1721-1726.

52. Sapir DA, Gorup JM. Radiofrequency medial branch neurotomy in litigant and nonlitigant patients with cervical whiplash. Spine 2001; 26:E268-E273.

53. Wallis B, Lord S, Bogduk N. Resolution of psychological distress of whiplash patients following treatment by radiofrequency neurotomy: A randomized, double-blind, placebo-controlled trial. Pain 1997; 73:15-22.

54. Ferrari R. Letter to the editor. Spine 2002; 27:327328.

55. Kaneoka K, Ono K, Inami S et al. Motion analysis of cervical vertebrae during whiplash loading. Spine 1999; 6:763-770. 